\title{
Studies of Binary Complexes of Metal Ions with 2, 2-Bipyridyl by Potentiometry
}

\author{
SHAIKH ABDUL RAHIM ${ }^{* 1}$, SAYYED HUSSAIN ${ }^{2}$, MAZAHAR FAROOQUI ${ }^{3}$ \\ ${ }^{1}$ Department of Chemistry, MIlliya College of Arts, Sci. \& Management Sci., \\ Beed, (M.S.), India \\ ${ }^{2}$ P.G. Department of Chemistry, Sir Syed College, Aurangabad, India \\ ${ }^{3}$ Dr. Rafiq Zakaria College for Women, Aurangabad, India \\ dr.ab6091@gmail.com
}

Received 2 August 2014 / Accepted 5 September 2014

\begin{abstract}
In biological systems transition metal ions exists in the form of different metal ligand complexes therefore investigations on the stability of metal complexes in relation with various structural features are important. Such type of study will help for understanding the driving forces leading to the formation of such complexes in the biological systems. Here we have reported systematic potentiometric studies on the formation of metal ligand complexes of transition metal ions with 2, 2- bipyridyl ligand in aqueous solution at $27{ }^{0} \mathrm{C}$ temperature in the presence of electrolyte $1 \mathrm{~N} \mathrm{NaNO}_{3}$. The protonation constant and metal ligand stability constants were determined using Irving Rossotti titration technique. Data obtained from titrations were analysed by SCOGS computer programs. The protonation constant values obtained by half integral method and point wise method are in agreement.
\end{abstract}

Keywords: Binary complex, Rossotti titration technique, 2, 2-Bipyridyl ligand

\section{Introduction}

Metal ions acts as cofactors in the regulation of enzymatic reactions. Interactions of metal ions with amino acid side chains or with different organic complexes is essential for many biological events. Complex formation occurs in biological fluids with ligands like amino acids, peptides. Copper complexes of phenanthroline have antitumor activities. 2,2Bipyridyl (Bpd) is used in analytical and preparative coordination chemistry. Heterocyclic nitrogen bases compete for transition metal ions. In order to obtain information on the driving forces leading to formation of metal complexes the binary complexation of bpd with metal ions was studied ${ }^{1}$. 2,2-Bipyridyl (bipyridines) are a family of chemical compounds with the formula $\left(\mathrm{C}_{5} \mathrm{H}_{4} \mathrm{~N}\right)_{2}$, which are formed by the coupling of two pyridine rings. Bpd is a popular ligand in coordination chemistry. The bipyridines are colourless solids, which are soluble in organic solvents and soluble in water. Bpd is a bidentate chelating ligand that forms complexes with most transition metal ions. Many of these complexes have distinctive optical properties and some are of interest for analysis. Bpd compounds that are widely used in chemical technology, biochemistry and especially analysis. Bpd is used in the manufacture 
of Diquat (herbicide). It is also used for the determination of iron. It is used for coatings, resins, drying agent, intermediate. Ruthenium complex and platinum complexes of bpd exhibit intense luminescence, which may have optical applications. It is also used in transition metal catalysis and aluminum initiated polymerization, redox indicator. Derivatives of bpd named as in amrinon and milrinone are used in the treatment of emergency heart condition ${ }^{2}$.

\section{Experimental}

The doubly distilled water used for preparations. The water is distilled in a glass distillation assembly with a pinch of potassium permanganate and potassium hydroxide to remove dissolved carbon dioxide and collected in amber colored bottle. $\mathrm{pH}$ of water obtained is within range 6.40-6.80. This fresh water was used for making solution and dilution.

The transition metal ions are used in the form of their nitrates to avoid the possibility of complex formation of metal ions with anions. The metal nitrates are prepared by dissolving the salt in a known volume of water. The potentiometric measurements of $\mathrm{pH}$ are performed using ELICO digital $\mathrm{pH}$ meter model L-120 with a combined glass electrode. The ionic strength was maintained using $1 \mathrm{~N} \mathrm{NaNO}_{3}$. The electrode is calibrated with standard buffer solutions $(\mathrm{pH}$ 4.01; 7.0 and 9.21) before and after each series of potentiometric titrations. The digital $\mathrm{pH}$ meter has a built in internal electronic voltage stabilizer for $\pm 10 \%$ fluctuations in the voltage supply. The instrument has inbuilt temperature compensator having the range $0-100{ }^{0} \mathrm{C}$ with an accuracy of $2^{0} \mathrm{C}$. The instrument can read $\mathrm{pH}$ in the range $0-14$ with an accuracy of \pm 0.01 $\mathrm{pH}$ units. The titration data numerically analyzed by SCOGS computer program.

The method of Irving and Rossotti has been used in the present investigation. The experimental procedure involves the titrations of following with the standard solution of $\mathrm{NaOH}(0.2 \mathrm{~N})$. The ionic strength of each solution is kept constant by the addition of $1 \mathrm{M} \mathrm{NaNO}_{3}$. Ligand concentration $0.01 \mathrm{M}$ and $\mathrm{HNO}_{3} 0.2 \mathrm{~N}$.

(1) Acid (A)- $\mathrm{HNO}_{3}$ (Nitric acid)

(2) Acid + Ligand (A+R)

(3) Acid + Ligand + Metal ion $(A+R+M)$

\section{Results and Discussion}

The observed $\mathrm{pH}$ values from above three titrations are then plotted against the volume of alkali added. Three titration curves are obtained (Figure 1), corresponding to the titrations mentioned in the experimental part. For the same volume of alkali, the ligand curve indicates lower values of $\mathrm{pH}$ than the acid curve. The metal chelate is formed in the reaction, the protons attached to the ligand displaced so that the metal complex titration curve indicates $\mathrm{pH}$ values lower than the ligand titration curve. Data from titration is analysed by SCOGS computer program to get protonation constant and metal ligand stability constant values. These values are tabulated in Table 1 and 2.

The Figure 1a shows that maximum value of $\bar{n} A$ is approximately two indicating that ligand has two replaceable protons. The protonation constant for bpd evaluated as 4.300 and 9.264. The ligand used is a bidentate. It provides two aromatic nitrogen whose unshared electron pairs are properly placed to act cooperatively in binding metal ions. This ligand is electron deficient they are excellent electron acceptors. High values of stability constants indicating that complexes formed are quite stable and it also reflects strong complexing capacity of the ligand. In most of the cases coloured complexes are formed with ligand bpd. Order of stability constant for present study is as follows: 

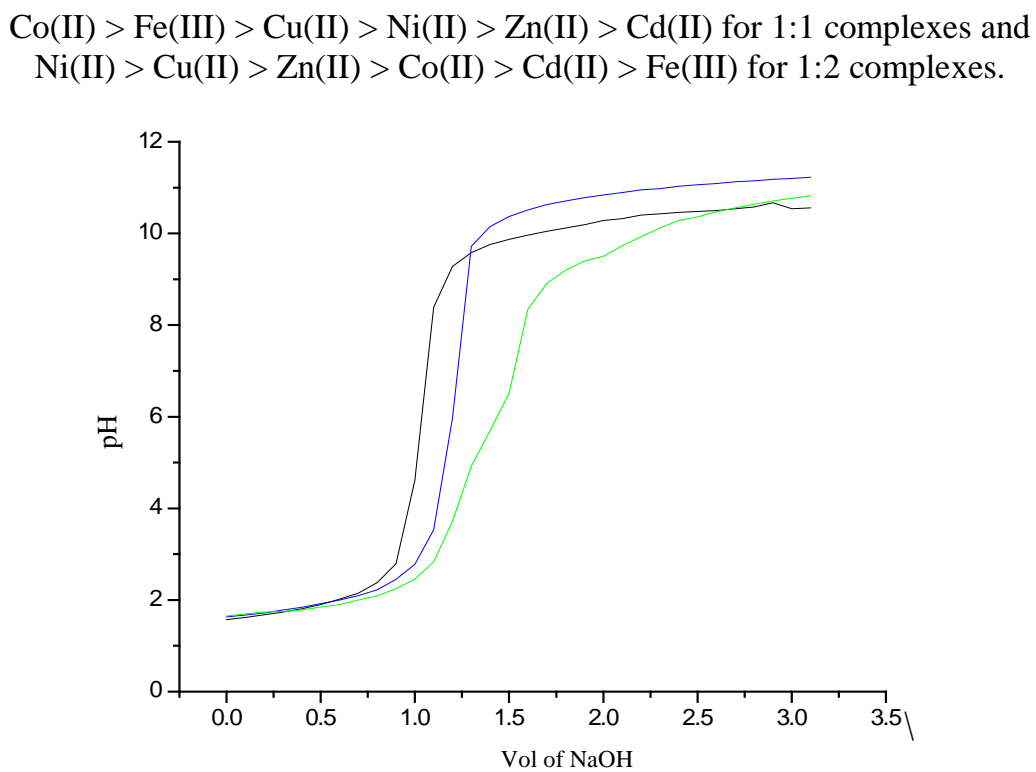

Figure 1. $\mathrm{pH}$ metric titration curve for metal [Co(II)] + Ligand[ M:L ratio (1:1)]

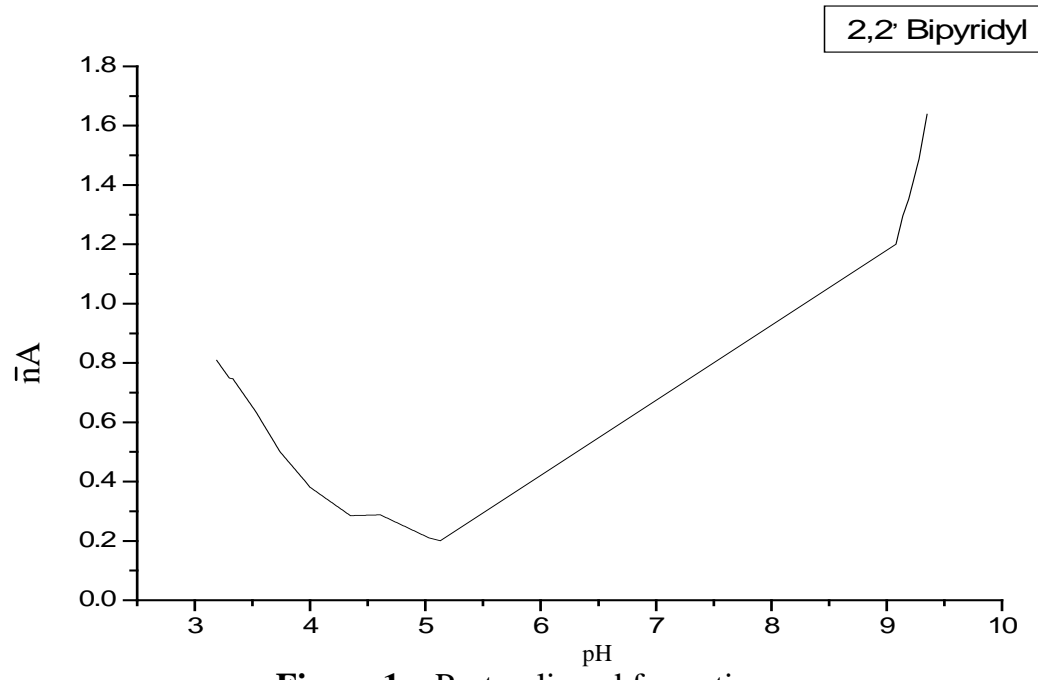

Figure 1a. Proton ligand formation curve

Table 1. Proton ligand constant and metal ligand stability constants for 2, 2-bipyridyl (1:1)

\begin{tabular}{ccccc}
\hline Proton Ligand & \multicolumn{4}{c}{ Metal ligand stability constants } \\
\cline { 2 - 5 } Constant & Metal ion & $\log \mathrm{K}_{1}$ & $\log \mathrm{K}_{2}$ & $\log \beta$ \\
\hline Half integral & $\mathrm{Cu}(\mathrm{II})$ & 5.6942 & 3.9872 & 9.6849 \\
$\mathrm{pK}_{1}=4.3001$ & $\mathrm{Zn}(\mathrm{II})$ & 3.4258 & 3.4168 & 6.8426 \\
$\mathrm{pK}_{2}=9.2643$ & $\mathrm{Ni}(\mathrm{II})$ & 4.2895 & 3.3521 & 7.6417 \\
Point wise & $\mathrm{Fe}(\mathrm{III})$ & - & 9.6659 & 9.6659 \\
$\mathrm{pK}_{1}=4.265$ & $\mathrm{Co}(\mathrm{II})$ & 11.3245 & 3.4273 & 14.7518 \\
$\mathrm{pK}_{2}=9.2312$ & $\mathrm{Cd}(\mathrm{II})$ & - & 3.4150 & 3.4150 \\
\hline
\end{tabular}


Table 2. Metal ligand stability constants for 2,2-biprydyl (1:2)

\begin{tabular}{cccc}
\hline \multirow{2}{*}{ Metal ion } & \multicolumn{3}{c}{ Metal ligand stability constants } \\
\cline { 2 - 4 } & $\log \mathrm{K}_{1}$ & $\log \mathrm{K}_{2}$ & $\log \beta$ \\
\hline $\mathrm{Cu}(\mathrm{II})$ & 3.2510 & 3.7118 & 6.9629 \\
$\mathrm{Zn}(\mathrm{II})$ & 3.2411 & 3.7059 & 6.9471 \\
$\mathrm{Ni}(\mathrm{II})$ & 3.2270 & 3.7605 & 6.9876 \\
$\mathrm{Fe}(\mathrm{III})$ & 3.7164 & - & 3.7164 \\
$\mathrm{Co}(\mathrm{II})$ & 3.1029 & 3.1311 & 6.2341 \\
$\mathrm{Cd}(\mathrm{II})$ & 3.1057 & 3.1027 & 6.2084 \\
\hline
\end{tabular}

The complexation of 2,2-bipyridyl with metal under study gives metal ligand stability constants which are shown in Table 1 and 2. Kapinos and Sigel ${ }^{3}$ studied properties of substituted pyridine molecules with metal ions in aqueous solution potentiometrically, they have got high stabilities for copper and zinc complexes, they have reported pKa value 3.91 for 4-bromo pyridine and 6.24 for 2, 3-dimethyl pyridine. The pKa values obtained in agreement with reported values. Pyridine and 2-methyl pyridine has pKa values of 5.17 and 5.97 due to presence of basic nitrogen. High stabilities have been reported for binary complexes of 2, 2-bipyridyl which is in agreement with literature ${ }^{4}$. High values of stability for iron(III) and $\mathrm{Cu}(\mathrm{II})$ complexes reported in our results in agreement with Guillermo et $a l .{ }^{5}$. The stability values for binary complex of iron are in agreement with the value determined by Mukherjee and Das ${ }^{6}$. They have reported two pKa values for bipyridyl and 1,10 phenanthroline as 4.23, 1.32 and 4.86, 1.90. The reported value for stability constant of iron complex as 9.13 which in agreement with our results.

Usha Nakara and Gupta ${ }^{7}$ have studied polarographically the complexes of cadmium(II) and Lead(II) with bpd in aqueous medium and reported high stability for cadmium(II) complexes. Ranjana et al. ${ }^{8}$ studied complexation of copper(II) with purines in the aqueous system, observed formation of coloured complexes, reported pKa values for adenine as 4.45, 9.4 and $6.77\left(\log \mathrm{K}_{1}\right)$ and $5.022\left(\log \mathrm{K}_{2}\right)$ for copper complexes .

Balraj Reddy et al. studied complexation of quinolinol and various ligands with nickel(II) in dioxane water medium at $30{ }^{\circ} \mathrm{C}$, and reported two pKa values for bpd 2.98 and 9.82 and formation of stable complexes with bpd $^{9}$.

The ligand may bound to metal ion by N-M sigma bond, beside there is also M-N pi bond formation by back donation of electrons from metal $\mathrm{d} \pi$ orbitals to vacant delocalized $\mathrm{p} \pi$ orbitals over the ligands. This $\mathrm{d} \pi-\mathrm{p} \pi$ interaction does not allow the concentration of the electrons on the metal ions to increase significantly the positive charges on the metal ions is almost same as in $\mathrm{M}^{2+}$. This leads to formation of more stable complexes. Kumar et al. ${ }^{10}$ prepared mixed ligand chelates of $\mathrm{Fe}(\mathrm{III})$ and $\mathrm{Co}(\mathrm{III})$ diphenates with 5-methyl -1, 10phenanthroline $(\mathrm{Ph})$ and 4-methyl $-2,2^{1}$-Dipridyl (4BDP), reported octahedral geometry. They also reported neutral nature of $\mathrm{Ph}$ 4BDP and the co-ordination through tertiary nitrogen. Better chelation tendancy of the ligand was mentioned. Thakur et al. ${ }^{11}$ studied interaction of the isoniazid with alkaline earth metals, reported two pKa values as 3.192 due to dissociation of nitrogen of pyridine ring and 10.66 due to dissociation of primary amino group and reported formation of 1:1 and 1:2 complexes.

Shrama et al. ${ }^{12}$ studied interaction of lanthanones with 2-amino pyridine and 4-amino pyridine. They reported two protonation constant as 6.91, 11.32 and 9.25, 11.47 respectively. Mohan et al. ${ }^{13}$ studied binary and mixed ligand complexes of various ligands with phosphonoformic acid, observed two pKa values for bpd and one for phen (phenanthroline) as 
1.52, 5.88 and 4.87, they also reported formation of 1:1 and 1:2 complexes. Beda and Helmut ${ }^{14}$ studied ternary complexes of pyr (pyridine) and bpd like ligands with transition metal ions, in aqueous solution, high stability values were found. They reported that the stability of the ternary complexes depends on the $\pi$-accepting qualities of the heteroaromatic $\mathrm{N}$ base, enhanced stability is lost if heteroaromatic $\mathrm{N}$ base replaced by an aliphatic amine. The pKa values determined by them are 7.14(2,2 bipyridyl amine), 2.69,5.18 (2,2'dipyridyl methane), 3.06 (2,2' dipyridyl ketone). They observed high stability for copper complexes. The order stability found by them was $\mathrm{Cu}(\mathrm{II})>\mathrm{Ni}(\mathrm{II})>\mathrm{Co}(\mathrm{II})>\mathrm{Zn}(\mathrm{II})$

Khalil et al. ${ }^{15}$ studied complexation of divalent metal ions with some Zwitter ionic buffers and triazoles at room temperature in aqueous medium, they reported complex formation occurred in stepwise manner and formation of 1:1 and 1:2 complexes. They observed two pKa values for 3-amino-1,2,4 triazole ( TRZAM ) 4.17 and 10.82 and observed that the stability constants of different 1:2 metal ligand complexes are lower than corresponding 1:1 system. The sequence of stability for bdp complexes with respect metal ions follows the order $\mathrm{Zn}$ (II) $>$ $\mathrm{Cu}(\mathrm{II})<\mathrm{Ni}$ (II) $<\mathrm{Co}$ (II) which in agreement with Irving William order.

\section{References}

1. Gabriel E B, Clara I T, Jesus E and Juan C S, J Histochem Cytochem.,1995, 43(5), 537-543; DOI: 10.1177/43.5.7730592

2. Naciye Turkel and Cigdem Sahim, Chem Pharm Bull., 2009, 57(7), 694-699;

DOI:10.1248/cpb.57.694

3. Larisa E Kapinos and Helmut Sigel, Inorganica Chimi Acta, 2002, 337, 131-142;

DOI: 10.1016/S0020-1693(02)00993-3

4. Kazuo Yamasaki and Motto Yasuda, J Am Chem Soc., 1956, 78(7), 1324; DOI: $10.1021 / j a 01588 a 016$

5. Guillermo Mendoza Diaz, Raul Perer Alonso and Rafael Espara, J Inorg Biochem., 1996, 64, 207-214; DOI: 10.1016/0162-0134(96)00041-4

6. $\quad$ Mukherjee G N and Ansuman Das, Proc Indian Acad Sci., 2002, 114(3), 163-174.

7. Usha Nakra and Gupta O P, Rasayan J Chem., 2009, 2(4), 853-860.

8. Ranjana Ghosh, Chattopadhaya M C and Arun Dey, Proc Indian National Sci Acad., 1980, 46(5)A, 486-493.

9. Balraj G, Shiva Raj and Ram Reddy M G, Asian J Chem., 1993, 5(4), 850-856.

10. Kuldeep Kumar, Naresh Pal and Gour N K, Orient J Chem., 2010, 26(3), 1123-1126.

11. Thakur S V, Farooqui M and Naikwade S D, Proc Nat Conf UTCS, 2013, 37-38.

12. Sangita Sharma, Dipika Dalwadi, Dhara Patel and Mahesh Kadia, Orient J Chem., 2008, 24(3), 875-882.

13. Srinivas M Mohan, Radha K, Laxami Kumari Y, Santhi Sudha K B and Jhansi Laxami P, Orient J Chem., 2007, 23(1), 195-204.

14. Beda E Fischer and Helmut Sigel, Inorgan Chem., 1979, 18(2), 425-428;

DOI: 10.1021/ic50192a047

15. Khalil M M, Radalla A G and Mohammed, J Chem Eng Data, 2009, 54, 3261-3272; DOI: $10.1021 / \mathrm{je} 9002459$ 